\title{
Briquetting of Dry Sugarcane Leaves by Using Press Mud, Cow Dung, and Buffalo Dung as Binders
}

\author{
Rahul A. Patil, ${ }^{1,2}$ Umesh B. Deshannavar $\mathbb{D}^{2},{ }^{2}$ M. Ramasamy, ${ }^{3,4}$ Sampath Emani, ${ }^{4}$ \\ Alibek Issakhov, ${ }^{5}$ and Nima Khalilpoor ${ }^{6}{ }^{6}$ \\ ${ }^{1}$ Chemical Engineering Department, D. Y. Patil College of Engineering and Technology, Kasaba Bavada, Kolhapur 416006, India \\ ${ }^{2}$ Chemical Engineering Department, KLE Dr. M. S. Sheshgiri College of Engineering and Technology, Belagavi 590008, India \\ ${ }^{3}$ Chemical Engineering Department, Universiti Teknologi PETRONAS, Bandar Seri Iskandar, Perak, Malaysia \\ ${ }^{4}$ Centre for Systems Engineering, Institute of Autonomous Systems, Universiti Teknologi PETRONAS, Bandar Seri Iskandar, \\ Perak, Malaysia \\ ${ }^{5}$ Faculty of Mechanics and Mathematics, Department of Mathematical and Computer Modelling, \\ Al-Farabi Kazakh National University, Almaty, Kazakhstan \\ ${ }^{6}$ Department of Energy Engineering, Graduate School of the Environment and Energy,Science and Research Branch, \\ Islamic Azad University, Tehran, Iran
}

Correspondence should be addressed toUmesh B.Deshannavar; deshannavar@gmail.com and Nima Khalilpoor; nimakhalilpoor@ gmail.com

Received 20 April 2021; Accepted 20 May 2021; Published 27 May 2021

Academic Editor: Alireza Baghban

Copyright $\odot 2021$ Rahul A. Patil et al. This is an open access article distributed under the Creative Commons Attribution License, which permits unrestricted use, distribution, and reproduction in any medium, provided the original work is properly cited.

The world's population is increasing rapidly. This means that energy consumption and demand for energy are also increasing at the same rate. It is estimated that energy will need to be provided to 9 to 10 billion people by 2040. India is a leading consumer of energy in the world. In particular, it consumes a large amount of oil and natural gas to fulfil its energy demand. Due to uncertainty in the supply of oil and natural gas and their prices as well as environmental pollution, there is a need to shift towards other energy sources. Biomass is one of the first energy sources with specific properties and abundant availability. Today, $10 \%$ to $14 \%$ of the world's energy supply is provided by biomass sources. Using agricultural waste (biomass) to make briquettes to generate power can be an alternative solution to the problems related to their disposal and pollution. The present work investigates the optimum ratio of dry sugarcane leaves to binders and optimum load and selects the best binder (cow dung, buffalo dung, and press mud) for making high-quality briquettes. The physical parameters and proximate analysis of the dry sugarcane leaf briquettes with the cow dung, buffalo dung, and press mud binders are investigated. The dry sugarcane leaf briquettes with the cow dung binder have the highest gross calorific value, net calorific value, split tensile strength, tumbling resistance, shatter resistance, and energy density ratio $\left(16262.31 \mathrm{~kJ} / \mathrm{kg}, 15362.1 \mathrm{~kJ} / \mathrm{kg}, 7.164 \mathrm{kN} / \mathrm{m}^{2}, 87.84 \%, 12.75 \%\right.$, and 0.9296 , respectively). The estimated results show that cow dung is a better binder for making high-quality dry sugarcane leaf briquettes than the buffalo dung and press mud binders.

\section{Introduction}

Energy is an important parameter in a civilian's life. Today, the lifestyle of civilians is largely dependent on energy and the amount of energy required by the population and industrial sector is increasing. The requirement for energy will always be higher than the energy supply. To fulfil the requirement for energy, there is thus a need to generate energy from various renewable resources [1]. To fulfil its demand for energy, India is largely dependent on oil and natural gas. Of total oil demand, $70 \%$ is imported, which affects the economy of the country [2]. Further, the use of oil and natural gas as a source of energy results in environmental pollution. Renewable sources are therefore an urgent solution for both pollution and economic problems. Examples of renewable sources are biomass, nuclear, hydro, tidal, geothermal, solar, and wind energy [3]. 
1.1. Source of Energy Biomass. Biomass, an organic matter or biological material derived from living organisms, is the best alternative to oil and natural gas. It can be transformed into solid, liquid, and gaseous biofuels that generate energy on burning [4]. Biomasses in different forms are available in large quantities in developing countries. Biomass accounts for $11.5 \%$ of energy demand and is expected to increase to between $15 \%$ and $50 \%$ by $2050[5,6]$. The cost of energy produced from biomass is relatively low [7]. The world's biomass energy potential in 2020 is presented in Table 1 [8].

Human waste, food processing, animal waste, agricultural waste, and forestry are examples of biomass [9]. In total, 320 million tonnes of agricultural waste such as dry sugarcane leaves, bagasse, rice straw, rice husks, wheat straw, and corncobs are produced by India. This residue is often burnt in an open atmosphere, creating smoke and fly ash problems. Approximately 100 million tonnes of agricultural waste are burnt in open fields, creating air pollution [10]. Burning this agricultural waste results in a huge loss of energy. However, the great task is converting this biomass into briquettes to generate energy [11-13].

1.2. Dry Sugarcane Leaves. Sugarcane plants are the best examples of how nature has provided us with renewable biomass to generate energy. Research has examined how such plants can be a substitute for coal, oil, and natural gas. For example, converting the waste of sugarcane plants into solid fuel such as briquettes could be the best solution to deforestation, which is a hot topic [14]. A large amount of sugarcane is produced globally, especially in India [15]. In 2015, 1877105 thousand metric tonnes of sugarcane were produced globally. India ranked in second place with 341200 thousand metric tonnes after Brazil (739267 thousand metric tonnes) with China in third (125536 thousand metric tonnes). The top 10 sugarcaneproducing countries are presented in Table $2[14,16]$ and the top three sugarcane-producing states in India are Uttar Pradesh, Maharashtra, and Karnataka (132427.6842, 69648.0768, and 35732 thousand metric tonnes, respectively). The top 10 sugarcane-producing states in India are presented in Table 3 [17].

The modification of the agricultural sector has produced a huge amount of waste, which has the potential to produce low-cost energy compared with oil and natural gas [18-21]. A large amount of agricultural waste is produced after cleaning sugarcane stems. This agricultural waste mostly consists of leaves and tops, which remain unused in the sugar production process [22]. Approximately 279 million metric tonnes of residue such as dry leaves and bagasse are generated by the sugarcane industry [15]. Although $3500 \mathrm{~kg}$ of dry sugarcane leaves is produced from one hectare of sugarcane crops and the gross calorific content of dry sugarcane leaves is $16919.667 \mathrm{~kJ} / \mathrm{kg}$, converting dry sugarcane leaves into biofuels has hardly been explored [23]. Dry sugarcane leaves are the major source of energy that could be used to make briquettes.

1.3. Briquetting. The technique of compacting loose biomass is known as briquetting $[12,14]$. Techniques include high-pressure and low-pressure briquetting. These are
TABLE 1: World's biomass potential [8].

\begin{tabular}{lc}
\hline Energy resource (biomass) & 2020 (metric tonnes) \\
\hline Crop residue & $480-499$ \\
Wood & $1791-2025$ \\
Energy crops & $2971-3535$ \\
Animal waste & 994 \\
Municipal waste & 516 \\
Total & $6752-7569$ \\
\hline
\end{tabular}

TABLE 2: Top 10 sugarcane producers [14-16].

\begin{tabular}{lcc}
\hline Rank & Country & Production (thousand metric tonnes) \\
\hline 1 & Brazil & 739267 \\
2 & India & 341200 \\
3 & China & 125536 \\
4 & Thailand & 100096 \\
5 & Pakistan & 63750 \\
6 & Mexico & 61182 \\
7 & Colombia & 34876 \\
8 & Indonesia & 33700 \\
9 & Philippines & 31874 \\
10 & USA & 27906 \\
\hline
\end{tabular}

TABle 3: Top 10 sugarcane-producing states in India [17].

\begin{tabular}{lcc}
\hline Rank & Country & Production (thousand metric tonnes) \\
\hline 1 & Uttar Pradesh & 132427.6842 \\
2 & Maharashtra & 69648.0768 \\
3 & Karnataka & 35732 \\
4 & Tamil Nadu & 33919.17 \\
5 & Andhra Pradesh & 15567 \\
6 & Bihar & 12741.42 \\
7 & Gujarat & 12690 \\
8 & Haryana & 7437 \\
9 & Uttarakhand & 6784.82 \\
10 & Punjab & 5919 \\
\hline
\end{tabular}

classified depending on the method applied to make briquettes, such as using a piston press, screw press, pellet mill, and hydraulic press. The types of binders used to make dry sugarcane leaf briquettes are starch, protein, fibre, fat/oil, lignin, cattle dung, press mud, molasses, and pulp and paper.

The objective of the present study was to explore different binders for making dry sugarcane leaf briquettes and examine the expediency of briquettes by determining their physical parameters and proximate analysis.

\section{Materials and Methods}

2.1. Material. Dry sugarcane leaves of species 86032 , which were used to make the briquettes, were collected from an agricultural field in Kolhapur, Maharashtra, India. Breed 86032 is cultivated in large quantities in Maharashtra and across India. The cow dung and buffalo dung binders used to make the briquettes were collected from a local dairy farm in western Maharashtra and the press mud binder was collected from a sugar manufacturer in western Maharashtra. 
2.2. Instruments. The following instruments were used to analyse the dry sugarcane leaves, cow dung, buffalo dung, press mud, and briquettes. A digital balance (model: SJ, Vibra, Mumbai, India) was used to weigh the required amount of briquettes. A hot air oven (model no.: Digital 1874, Lab Hosp, Mumbai, India) was used to measure the moisture content of the sample. A muffle furnace (model no.: 591010, Shital Scientific Ind., Mumbai, India) was used to determine the volatile matter and ash content. The gross calorific value (GCV) was measured using a bomb calorimeter (model: BCA, Dynamic Engineering, Mumbai, India). A tumbling machine (Shital-Gayatree Enterprise, Rajkot, India) was used to measure the tumbling resistance (TR). Split tensile strength (STS) was measured using a hydraulic press (model no.: TUE-C400, Fine Spavy Associates Pvt. Ltd., Miraj, India).

2.3. Experimental Setup. A hydraulic press or universal testing machine (model no.: UTM-86/08/003, Superfine Testing Equipment, Kolhapur, India) was used to make the briquettes. A cutting machine (Arihant Fabrication and Engineering, Minache, Kolhapur, India) was used to cut the dry sugarcane leaves. A digital weight balance (model no.: PNM101, Padmini Industries, Sangli) was used to measure the required amount of the sample. The dry sugarcane leaves and binders were placed in a die of $0.15 \mathrm{~m}$ inner diameter and $0.13 \mathrm{~m}$ height. The sample was compressed with a block of $0.147 \mathrm{~m}$ diameter and a height of $0.075 \mathrm{~m}$. The die and block were held between two plates of $0.117 \mathrm{~m}$ in diameter on the universal testing machine.

\subsection{Methodology}

2.4.1. Experimental Procedure for Making Dry Sugarcane Leaf Briquettes from Different Binders. First, $0.2 \mathrm{~kg}$ of dry sugarcane leaves was weighed by using an electronic weighing balance. The dry sugarcane leaves were mixed with $1 \mathrm{~kg}$ of the binder (cow dung, buffalo dung, and press mud binders separately). The mixture was placed in the die and the block was adjusted over the sample. The load was gradually applied to the sample. At a high load, the original moisture present in the sample came out along with some of the binder. This load was $22 \mathrm{kN}$ for the cow dung binder, $11 \mathrm{kN}$ for the buffalo dung binder, and $12 \mathrm{kN}$ for the press mud binder. After the removal of the sample from the die, the briquette was disintegrated. Further experiments were carried out at a lower load $(20 \mathrm{kN}$ for the cow dung binder, $9 \mathrm{kN}$ for the buffalo dung binder, and $10 \mathrm{kN}$ for the press mud binder).

The experiments were conducted for the following weight ratios of dry sugarcane leaves to binders: $1: 0.5,1: 1$, $1: 1.5,1: 2,1: 2.5,1: 3,1: 3.5,1: 4,1: 4.5$, and $1: 5$. The optimum weight ratio was chosen depending on the briquette formation. The optimum weight ratio of the dry sugarcane leaves to the cow dung binder was $1: 3.5$, to the buffalo dung binder was $1: 4$, and to the press mud binder was $1: 2$. These were the ratios at which suitable briquette formation took place. The optimum weight ratio samples were applied with different loads. A suitable briquette formation took place for the cow dung binder at $18 \mathrm{kN}$, the buffalo dung binder at $9 \mathrm{kN}$, and the press mud binder at $10 \mathrm{kN}$. Before the optimum load, no briquette formation occurred. Then, the sample was tested by adding water $(1 \mathrm{ml}$ and $2 \mathrm{ml}$ ). When the water was added to the sample, moisture came out along with some of the binder and the briquette was disintegrated after it was removed from the die. The dry sugarcane leaf briquettes with the cow dung binder (DSL/CD), buffalo dung binder (DSL/BD), and press mud binder (DSL/PM) were analysed based on the optimum weight ratios and optimum load.

\subsection{Analytical Procedure}

\subsubsection{Physical Parameters}

(1) Bulk density (BD): the BD of the briquettes was determined by using a standard procedure. An empty container with a known volume was weighed. The container was then filled with the sample and weighed. The BD was calculated using the following equation [24]:

$$
\text { bulk density }\left(\mathrm{kg} / \mathrm{m}^{3}\right)=\frac{\left(W_{2}-W_{1}\right)}{V},
$$

where $W_{2}$ is the weight of the container + sample, $W_{1}$ is empty weight of the container, and $V$ is the volume of the container.

(2) Relaxed density (RD) or BD of the briquettes by geometric measurements: if the briquettes are cylindrical, their density can be calculated from their geometry. The $\mathrm{RD}$ was calculated using the following formula [24]:

relaxed density $\left(\mathrm{kg} / \mathrm{m}^{3}\right)=\frac{\text { weight of briquette }}{(\pi / 4) \times D^{2} \times H}$,

where $D$ is the diameter of the briquette and $H$ is the height of the briquette.

(3) $\mathrm{BD}$ of briquettes by using the water displacement method: the briquettes were coated with an adhesive tape (cellux self-adhesive tape) to prevent any water penetration when submerged in water. The weights of the briquettes were measured before and after coating with the tape. The coated briquette was submerged in water and the volume of the water displaced was measured. The $\mathrm{BD}$ of the briquettes was obtained using the following formula: 
bulk density $\left(\mathrm{kg} / \mathrm{m}^{3}\right)=\frac{\text { (weight of coated briquette }- \text { weight of briquette })}{\text { volume of water displaced }}$.

(4) Degree of densification (DD): the DD is the bounding ability of biomass. It increases in the density of dry sugarcane leaves and binders due to briquetting. It was calculated using the following equation [25]:

$$
\text { degree of densification }=\frac{(\text { density of briquette }- \text { density of dry sugarcane leaves })}{\text { density of dry sugarcane leaves }} .
$$

(5) Compression ratio (CR): the $\mathrm{CR}$ is the ratio of the density of a briquette to the density of dry sugarcane leaves. As the briquetting load increases, the CR increases in a similar manner to the BD [25].

(6) STS: STS is the maximum load at which the failure of a briquette takes place. A briquette was held between two parallel flat plates. A gradually increasing load was applied using a hydraulic press (model no.: TUE-C400, Fine Spavy Associates Pvt. Ltd., Miraj, India) until the failure of the briquette took place. The load at which the failure of the briquette took place was noted. STS was calculated using the following formula [26]:

$$
\text { split tensile strength }\left(\mathrm{kN} / \mathrm{m}^{2}\right)=\frac{(2 \times P)}{\pi \times D \times L},
$$

where $P$ is the load at which cracking occurs, $D$ is the briquette diameter, and $L$ is the briquette length.

(7) TR test: the TR is the resistance to the stress or force of a briquette. The weight of the briquette was measured and placed in the metallic cylinder of $0.2 \mathrm{~m}$ inner diameter and $0.24 \mathrm{~m}$ length. The opening on the top of the cylinder was closed. The cylinder was rotated in the tumbling machine (Shital-Gayatree Enterprise, Rajkot, India) at $70 \mathrm{rpm}$ for 5 minutes. The weight of the briquette after the tumbling test was noted and the TR was calculated using the following equation [25]:

$$
\text { weight loss }(\%)=\frac{\left(W_{3}-W_{4}\right)}{W_{3} \times 100},
$$

where $W_{3}$ is the weight of the briquette before the tumbling test and $W_{4}$ is the weight of the briquette after the tumbling test.

tumbling resistance $(\%)=100-\%$ weight loss.

(8) Shatter resistance (SR) test: the hardness of a briquette is determined using an SR test. The weight of the briquette before the SR test was measured. The sample was then dropped on a concrete floor from a $1 \mathrm{~m}$ height. The procedure was repeated for 10 drops. The weight of the briquette after 10 drops was measured. The SR of the briquette was calculated using the equations given below [25]:

$$
\text { weight loss }(\%)=\frac{\left(W_{5}-W_{6}\right)}{W_{5} \times 100},
$$

where $W_{5}$ is the weight of the briquette before the shatter test and $W_{6}$ is the weight of the briquette after the shatter test.

$$
\text { shatter resistance }(\%)=100-\% \text { weight loss. }
$$

\subsubsection{Proximate Analysis}

(1) Moisture content: the moisture content was measured by using a standard method (ASTM). The weight of the briquette before drying was measured and then the briquette was placed in an oven (model no.: Digital 1874, Lab Hosp, Mumbai, India) at $378 \mathrm{~K}$ for 240 to 300 minutes until a constant weight was reached. The weight of the sample after drying was noted. This method of measuring the moisture content is called the oven drying method. The moisture content of the sample was calculated using the following equation [25]:

$$
\text { moisture content }(\%)=\frac{\left(W_{8}-W_{9}\right)}{\left(W_{8}-W_{7}\right)} \times 100 \text {, }
$$

where $W_{7}$ is the weight of the crucible, $W_{8}$ is the weight of the crucible + sample before drying, and $W_{9}$ is the weight of the crucible + sample after drying.

(2) Volatile matter: the dried briquette left from the procedure described in Section 2.4.1 was used to calculate the volatile matter. The crucible with the dried sample was covered with a lid. Then, it was placed in a muffle furnace (model no.: 591010, Shital Scientific Ind., Mumbai, India) at $873 \mathrm{~K}$ for 10 minutes according to the standard method (ASTM). The crucible was removed from the furnace and cooled in air and then in desiccators. The weight of the crucible was noted. The percentage of the volatile matter was calculated using the following formula [25]: 


$$
\text { volatile matter }(\%)=\frac{\left(W_{12}-W_{13}\right)}{\left(W_{11}-W_{10}\right)} \times 100
$$

where $W_{10}$ is the weight of the crucible, $W_{11}$ is the weight of the crucible + sample, $W_{12}$ is the weight of the crucible + sample in the muffle furnace, and $W_{13}$ is the weight of the crucible + sample after heating.

(3) Ash content: the residual sample from the volatile matter content was heated without a lid in a muffle furnace at $973 \mathrm{~K}$ for 240 to 300 minutes until a constant weight was reached. The crucible was removed from the furnace and cooled in air and then in desiccators. The percentage of the ash content was calculated following ASTM standards. The weight of the crucible was recorded. The percentage of the ash content was calculated using the following formula [25]:

$$
\operatorname{ash} \operatorname{content}(\%)=\frac{\left(W_{16}-W_{14}\right)}{\left(W_{15}-W_{14}\right)}
$$

where $W_{14}$ is the weight of the crucible, $W_{15}$ is the weight of the crucible + sample, and $W_{16}$ is the weight of the crucible + ash.

(4) Fixed carbon content: the percentage of the fixed carbon content was determined using the following equation [25]:

$$
\text { fixed carbon }(\%)=100-\%(\text { ash content }+ \text { volatile matter }+ \text { moisture content }) \text {. }
$$

(5) GCV: the GCV was measured by using a standard procedure (ASTM). The complete combustion of the sample was carried out in an adiabatic bomb calorimeter (model: BCA, Dynamic Engineering, Mumbai, India) at 25 atm of oxygen. To measure the water equivalent of the apparatus, a powder of
$0.01 \mathrm{~kg}$ of pure and dry benzoic acid was burnt in a bomb calorimeter under the same conditions. Altogether, 6324 calories/gm of the calorific value of benzoic acid was taken. The GCV was determined using the following formula:

$$
\mathrm{GCV}(\mathrm{kJ} / \mathrm{kg})=\frac{(\text { calorimeter constant } \times \text { rise in temperature })}{X} \times 100,
$$

where $X$ is the mass of the sample briquette taken in the crucible.

(6) Net calorific value (NCV): the NCV was calculated as follows:

net calorific value $(\mathrm{kJ} / \mathrm{kg})=\mathrm{GCV}-(52.83 \times \%$ of hydrogen $)$.
2.5.3. Energy Density Ratio (EDR). The EDR measures the energy content per unit volume of a briquette. The $\mathrm{BD}$ and GCV were used to calculate the EDR [13]:

$$
\text { energy density ratio }=\frac{\text { energy content of briquette }\left(\mathrm{kJ} / \mathrm{m}^{3}\right)}{\text { energy content of dry sugarcane leaves }\left(\mathrm{kJ} / \mathrm{m}^{3}\right)} \text {. }
$$

\section{Results and Discussion}

The physical analysis and proximate analysis were carried out after one week of briquette production. The briquettes were sun-dried at a temperature between 305 and $310 \mathrm{~K}$ and a humidity between $62 \%$ and $69 \%$.

\subsection{Physical Parameters of the Briquettes with Different Binders}

3.1.1. BD of the Briquettes. Figure 1 shows that the highest $\mathrm{BD}$ was $216.8 \mathrm{~kg} / \mathrm{m}^{3}$ for DSL/BD. The BDs for DSL/CD and DSL $/ \mathrm{PM}$ were $198.1 \mathrm{~kg} / \mathrm{m}^{3}$ and $191.9 \mathrm{~kg} / \mathrm{m}^{3}$, respectively. A 


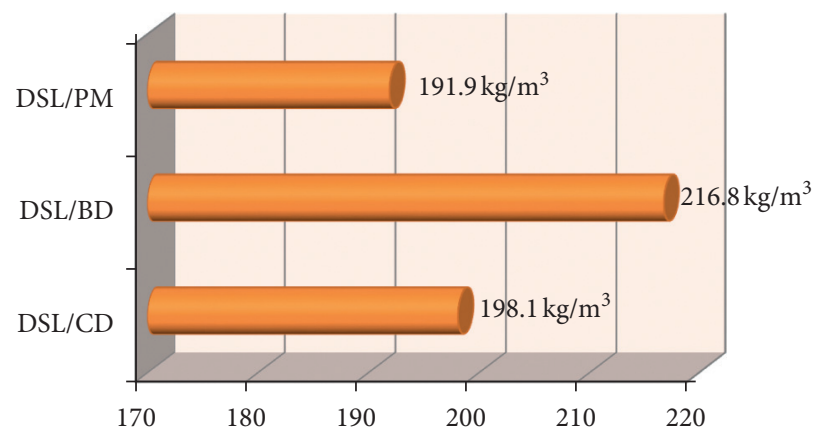

Figure 1: BDs of the briquettes with different binders.

high-quality briquette should have a high $\mathrm{BD}$, which will burn for longer periods, have a high content energy per volume, and be easy to handle and store [27]. Due to the high load application, a solid bridge may be developed between particles. van der Waals forces developed with the help of moisture also aggregate the particles. Lignin, which is present in dry sugarcane leaves and the buffalo dung binder, acts as a binding agent and helps the binding process. At a high load, lignin comes from the biomass particles and helps form a solid bridge between them [28]. Because of this process, the $\mathrm{BD}$ of $\mathrm{DSL} / \mathrm{BD}$ is high. As the amount of the binder in the briquettes increases, the $\mathrm{BD}$ increases. It also depends on the load applied for briquetting [29]. The proportion of the buffalo dung binder present in the dry sugarcane briquette is $18.12 \%$. The load applied to make a briquette is $9 \mathrm{kN}$. The $\mathrm{BDs}$ of DSL/BD and DSL/CD are higher than that of wheat straw bale briquettes, reported to be $100 \mathrm{~kg} / \mathrm{m}^{3}$ to $120 \mathrm{~kg} / \mathrm{m}^{3}$ [29].

\subsection{2. $R D$ or $B D$ of the Briquettes by Geometric Measurements.} Figure 2 shows that as the load increases, the height of a briquette decreases. This decrease in height reduces the volume of the briquette. Therefore, the RD decreases [30]. The volumes of DSL/CD and DSC/BD were found to be $0.00257 \mathrm{~m}^{3}$ and $0.002629 \mathrm{~m}^{3}$, respectively. The $\mathrm{RD}$ was found to be low for DSL/CD, $169.40 \mathrm{~kg} / \mathrm{m}^{3}$, and high for DSL $/ \mathrm{BD}, 174.95 \mathrm{~kg} / \mathrm{m}^{3}$. The RD for DSL $/ \mathrm{PM}$ was $171.31 \mathrm{~kg} /$ $\mathrm{m}^{3}$. The RDs of DSL/CD, DSL/BD, and DSL/PM were higher than those of cotton stalk, sunflower stalk, and ground nutshell briquettes, reported to be $94.58 \mathrm{~kg} / \mathrm{m}^{3}, 111.78 \mathrm{~kg} /$ $\mathrm{m}^{3}$, and $90.127 \mathrm{~kg} / \mathrm{m}^{3}$, respectively [30].

3.1.3. BD of Briquettes Using the Water Displacement Method. The BD when using the water displacement method depends on the size and shape of a particulate solid. When a solid is submerged in water, the volume of water displaced is the same as the volume of the solid particle $[31,32]$. As the volume of DSL/BD was more, the BD when using the water displacement method of DSL/BD had the highest value, whereas the equivalent BDs of DSL/CD, DSL/ $\mathrm{BD}$, and DSL $/ \mathrm{PM}$ were $3.28 \mathrm{~kg} / \mathrm{m}^{3}, 3.46 \mathrm{~kg} / \mathrm{m}^{3}$, and $1.923 \mathrm{~kg} /$ $\mathrm{m}^{3}$, respectively, as shown in Figure 3. A high-quality briquette should have a higher $\mathrm{BD}$ when using the water displacement method [33].

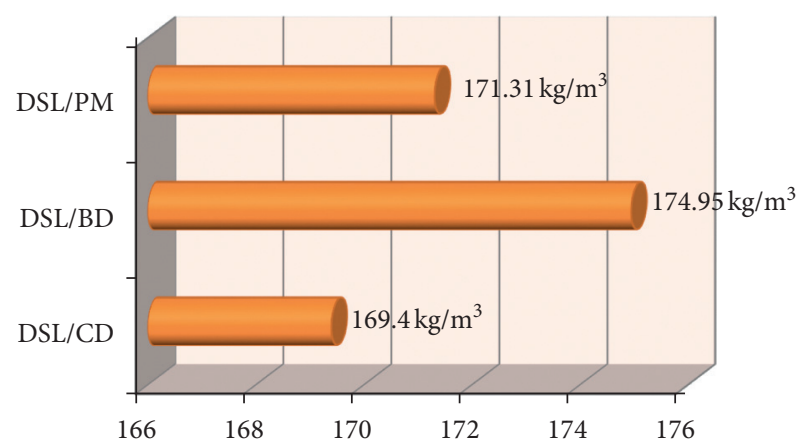

Figure 2: RDs of the briquettes with different binders.

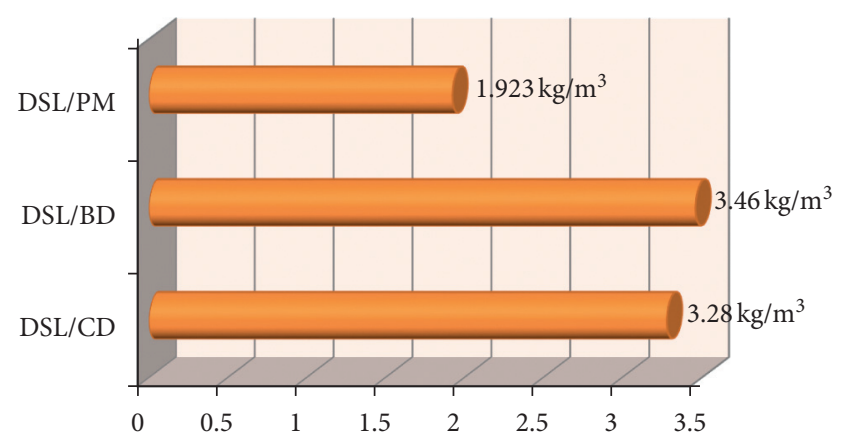

FIGURE 3: BDs of the briquettes with different binders when using the water displacement method.

3.1.4. $D D$ of the Briquettes. The $\mathrm{DD}$ is the ratio of the difference in the density of a briquette and the raw material to the density of the raw material. To calculate the DD, the $\mathrm{BDs}$ of the briquettes and dry sugarcane leaves were used. Figure 4 shows that the DD of DSL/CD was 0.033 , that of $\mathrm{DSL} / \mathrm{BD}$ was 0.1315 , and that of DSL/PM was 0.00156 . The $\mathrm{DD}$ is the bounding ability of biomass, and it depends on the load applied and particle size $[25,34]$. The highest DD was found to be for DSL/BD.

3.1.5. CR of the Briquettes. The CR is the ratio of the density of a briquette to the density of the raw material. The BDs of the briquettes and dry sugarcane leaves were considered to calculate the CR. The highest CR of 1.131 was found for DSL/ $\mathrm{BD}$ and the lowest CR of 1.0015 was found for DSL/PM; the CR for DSL/CD was 1.033, as shown in Figure 5. As the 


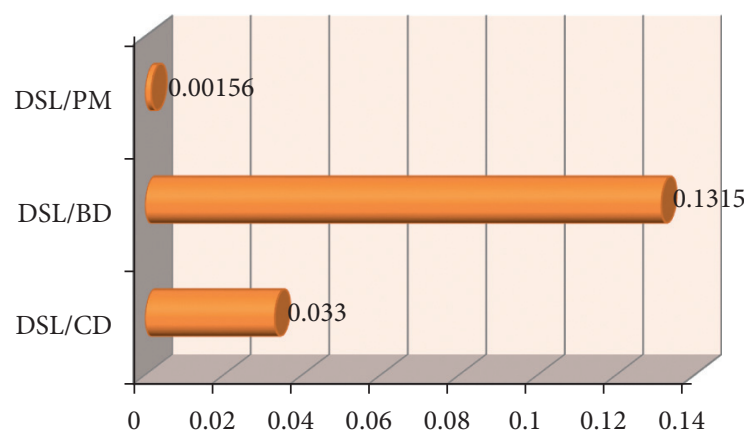

Figure 4: DD of the briquettes with different binders.

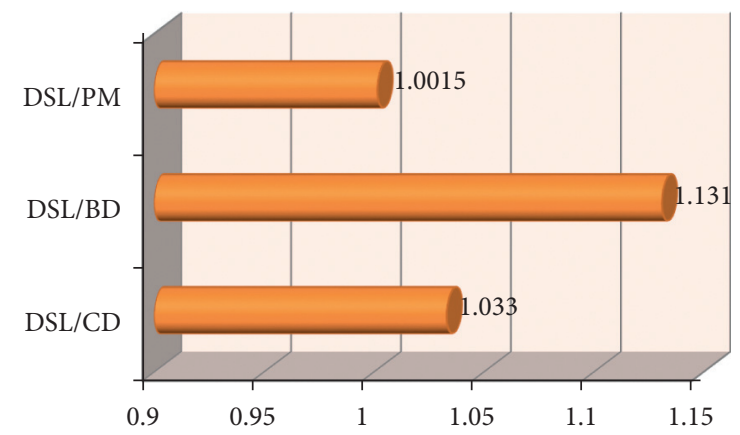

FIGURE 5: CRs of the briquettes with different binders.

briquetting load increased, the CR increased in a similar manner to the BD. A high CR is good for packing briquettes. The CRs recorded for the other briquettes were 3.80 for rice husk briquettes and 4.2 for groundnut briquettes $[35,36]$.

3.1.6. STS of the Briquettes. The STSs of DSL/CD, DSL/BD, and DSL/PM were found to be $7.164 \mathrm{kN} / \mathrm{m}^{2}, 5.59 \mathrm{kN} / \mathrm{m}^{2}$, and $6.98 \mathrm{kN} / \mathrm{m}^{2}$, respectively, as shown in Figure 6 . The cellulosic and hemicellulosic fibres present in the cow dung binder were $1.10 \%$ and $13.10 \%$, respectively, higher than those of the buffalo dung and press mud binders. During the compression load, fibres become twisted or entrapped and fold over each other to interlock. This interlocking increases the resistance to the STS test [37]. The STS of the briquettes increased with an increasing binder percentage and dry sugarcane leaf percentage, which itself is a high-density material [38]. With an increasing load during briquette making, the STS of the briquettes increased due to plastic deformation. The load applied to make the briquettes with the cow dung binder was $18 \mathrm{kN}$, higher than the load used to make the DSL/BD and DSL/PM briquettes. STS may also depend on the physical properties of biomass. High STS was observed for DSL/CD, which is good for transporting and storing briquettes [39].

3.1.7. TR of the Briquettes. The TR is the resistance to the stress or force of a briquette. Figure 7 shows that the TR for DSL/CD was $87.84 \%$, that for DSL/BD was $84.13 \%$, and that for DSL/PM was $86.66 \%$. The maximum TR was thus for DSL/CD. A high-quality briquette should have a high TR for

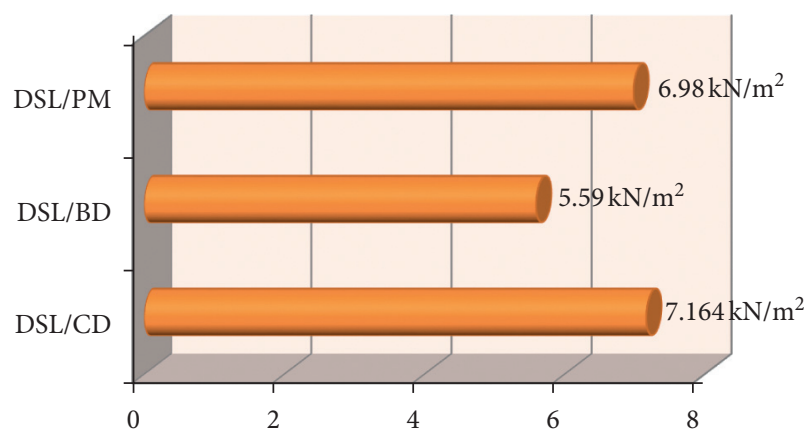

FIgURE 6: STS of the briquettes with different binders.

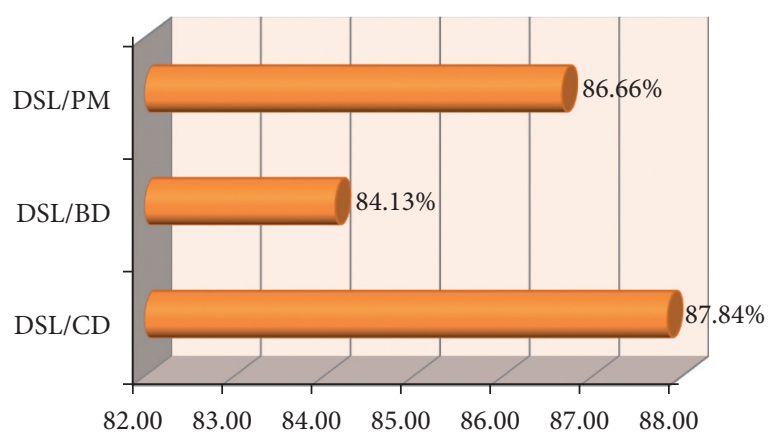

(\%)

FIgURE 7: TR of the briquettes with different binders.

ease of handling, transportation, and storage. The increase in the TR was due to the binder percentage in the briquettes and application of a high load during briquette making [40]. The percentage of the binder and load applied to make DSL/ CD were $20.55 \%$ and $18 \mathrm{kN}$, higher than those of DSL/BD and DSL/PM.

3.1.8. SR of the Briquettes. The hardness of the briquette was determined by using the SR test to measure its resistance to impact. The DSL/CD showed some resistance to impact and DSL/BD and DSL/PM disintegrated after the drops, as shown in Table 4. The SR is useful for loading and unloading the briquettes from trucks as well as storing in silos and bins [28]. The increase in the TR is due to the binder percentage in the briquettes and application of a high load during briquette making [41, 42]. The percentage of the binder and load applied to make DSL/CD were $20.55 \%$ and $18 \mathrm{kN}$, higher than those of DSL/BD and DSL/PM.

\subsection{Proximate Analysis of the Briquettes with Different} Binders. The values of the fixed carbon, volatile matter, and ash content of the briquettes depend on the composition of the dry sugarcane leaves and binders. A change was observed by mixing heterogeneous materials [43].

3.2.1. Moisture Content of the Briquettes. The briquettes were difficult to handle after their removal from the die. They were sun-dried for one week at a temperature between 305 and $310 \mathrm{~K}$ and a humidity between $62 \%$ and $69 \%$. After 
TABLE 4: SR test.

\begin{tabular}{lcc}
\hline Sr. no. & Briquette & SR (\%) \\
\hline 1 & DSL/CD & 12.75 \\
2 & DSL/BD & Disintegrated after seven drops \\
3 & DSL/PM & Disintegrated after six drops \\
\hline
\end{tabular}

drying, the briquettes were easy to handle. The moisture content of the briquettes was observed to be $25.61 \%$ for DSL/ $\mathrm{CD}, 33.89 \%$ for DSL/BD, and $6.52 \%$ for DSL/PM, as shown in Figure 8 . This percentage of moisture should be reduced to less than $18 \%$ before combustion to generate the maximum heat [44]. In the briquette-making process, water is a natural binding agent present in binders. This helps develop the van der Waals forces between the particles to bind them together. However, higher moisture content briquettes are difficult to handle. Therefore, a suitable moisture content in a briquette is important for easy handling and making the briquette stable. It has been reported that an increase in the calorific value of a briquette can be because of a lower moisture content [45]. The lower moisture content in the briquettes was caused by removing the moisture from the mixture by compression during briquette making [46]. The lowest moisture content was observed to be for DSL/PM.

3.2.2. Ash Content of the Briquettes. The impurity left after combustion is called ash. The ash content of the briquettes increased by increasing the percentage of the binder in the briquette. A low ash content increases the calorific value of the briquette, ensures suitable thermal and biological conversion, and lowers the corrosion of equipment [47]. The ash content also affects the oxygen diffusion and heat transfer of the briquette [48]. Figure 9 shows that the ash contents of DSL/CD, $\mathrm{DSL} / \mathrm{BD}$, and DSL/PM were $10.99 \%, 9.86 \%$, and $18.88 \%$, respectively. The ash content was found to be low for DSL/BD because the original ash content of the buffalo dung binder was $4.23 \%$ lower than that of the cow dung and press mud binders. The binder percentage in the briquettes was $18.12 \%$ lower than those of DSL/CD and DSL/PM. The ash contents for DSL/BD and DSL/CD were lower than those of sugarcane leaf and rice straw briquettes, recorded as $12.85 \%$ [43].

3.2.3. Fixed Carbon Content of the Briquettes. The fixed carbon content is the solid fuel (coal) available for combustion after the vaporisation of the volatile matter. A higher value of the fixed carbon content has a positive effect on the calorific value. It adds to heat generation during briquette burning [49]. Figure 10 shows that the fixed carbon content was $2.93 \%$ for $\mathrm{DSL} / \mathrm{CD}, 7.96 \%$ for $\mathrm{DSL} / \mathrm{BD}$, and $6.87 \%$ for DSL/PM. The fixed carbon contents of DSL/BD and DSL/ $\mathrm{PM}$ were more than that of coconut leaf briquettes, which was found to be $4.72 \%$. This value is encouraging, as it can lengthen the energy release [50].

3.2.4. Volatile Matter Content of the Briquettes. The volatile matter contents of DSL/CD, DSL/BD, and DSL/PM were found to be $60.47 \%, 48.29 \%$, and $67.73 \%$, respectively, as shown in Figure 11 . This is equivalent to the components of carbon, hydrogen, and oxygen, which can result in easy ignition and increase the flame length. A low volatile matter content results in incomplete combustion, which results in smoke and harmful gas emissions. The volatile matter recorded for rice husk briquettes was $68.20 \%$, that for sawdust charcoal briquettes was $71 \%$, and that for rice straw/sugarcane leaf briquettes was $74.67 \%$ [50-52]. DSL/CD and DSL/PM met the requirement of the volatile matter content of the briquettes. Most of the briquettes are converted into vapor and burn as gas in the combustion chamber [51]. The maximum volatile matter content was found to be $67.73 \%$ in the briquettes with the press mud binder (DSL/PM).

3.2.5. GCV of the Briquettes. The GCV is the heat generated by combustion when the water produced is allowed to return to the liquid state. The GCV is an important property of highquality briquettes. The GCV depends on the composition and GCV values of the raw material [53] as well as the moisture content of the briquette [45]. At a high compression load, the dry sugarcane leaf briquettes reported good heat content [44]. The maximum GCV $(16262.308 \mathrm{~kJ} / \mathrm{kg})$ was for DSL/CD. The minimum GCV was found to be $15257.428 \mathrm{~kJ} / \mathrm{kg}$ for DSL $/ \mathrm{PM}$. The GCV of DSL/BD was $16232.999 \mathrm{~kJ} / \mathrm{kg}$, as shown in Figure 12. The GCVs of DSL/CD, DSL/BD, and DSL/PM were found to be higher than those of rice husk briquettes, ground nut shell briquettes, cowpea briquettes, and soybean briquettes, which were measured as $15175 \mathrm{~kJ} / \mathrm{kg}, 12600 \mathrm{~kJ} / \mathrm{kg}$ [54], $14372.93 \mathrm{~kJ} / \mathrm{kg}$, and $12953 \mathrm{~kJ} / \mathrm{kg}$, respectively $[55,56]$. The GCVs of DSL/CD, DSL/BD, and DSL/PM are much higher for domestic and industrial applications. The maximum GCV briquette burns without difficulty and is superior to the low GCV [55].

3.2.6. NCV of the Briquettes. The NCV is the heat generated by combustion when the water produced remains in vapour form. The NCV is an important property of a briquette. It is contingent on its GCV, moisture content, and hydrogen content. Nitrogen, oxygen, and the ash content have less effect on the NCV [53]. A maximum NCV briquette burns without difficulty and is superior to a low NCV [55]. The maximum $\mathrm{NCV}$ was found to be $15362.103 \mathrm{~kJ} / \mathrm{kg}$ for DSL/CD. The minimum NCV was found to be $13473.766 \mathrm{~kJ} / \mathrm{kg}$ for DSL/BD. The NCV was $13972.019 \mathrm{~kJ} / \mathrm{kg}$ for DSL/PM, as shown in Figure 13. A high-quality briquette should have a higher NCV.

3.3. EDR of the Briquettes. The EDR is the energy content of a briquette fuel per unit volume to the energy content of the raw biomass per unit volume [25]. To calculate the EDR, the GCV and BD were used. Figure 14 shows that the highest EDR was found to be 0.9296 for DSL/CD and the lowest EDR was found to be 0.8478 for DSL/BD. The EDR was 0.9003 for DSL/PM.

3.4. Comparison of $D S L / C D, D S L / B D$, and DSL/PM for Selecting the Best Binder. This research aimed to find the best binder for making high-quality dry sugarcane leaf briquettes. Table 5 compares the physical parameters, proximate 


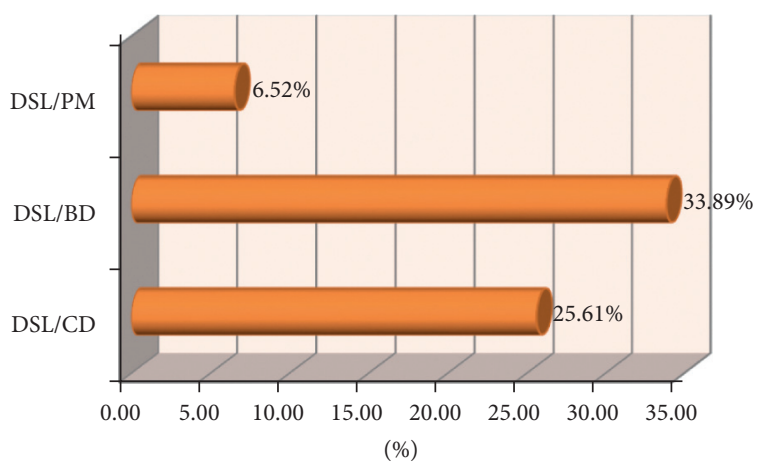

FIGURE 8: Moisture content of the briquettes with different binders.

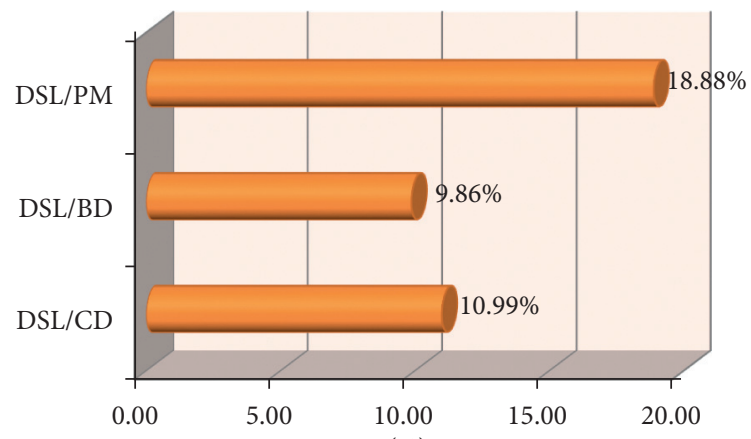

(\%)

Figure 9: Ash content of the briquettes with different binders.

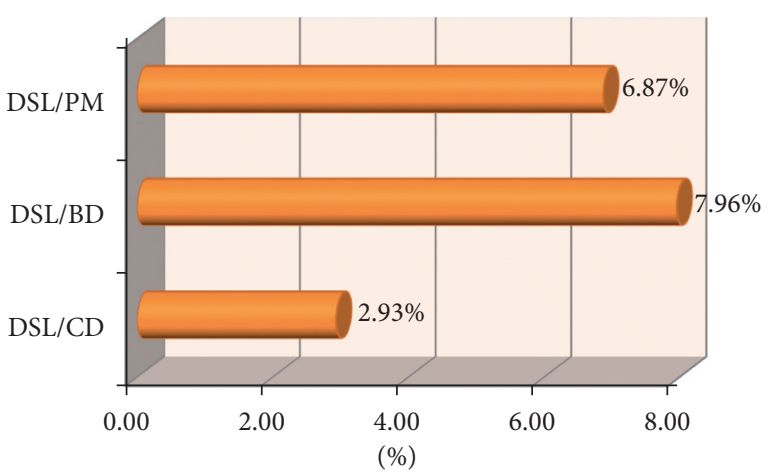

Figure 10: Fixed carbon content of the briquettes with different binders.

analysis, and ultimate analysis of DSL/CD, DSL/BD, and DSL/PM.

High-quality briquettes for domestic and industrial applications require higher values of the GCV, NCV, BD, STS, TR, SR, and EDR and lower values of moisture content and ash content. All briquettes should have these main properties. The other properties such as the fixed carbon content and volatile matter, which contribute to the GCV, should also have higher values.

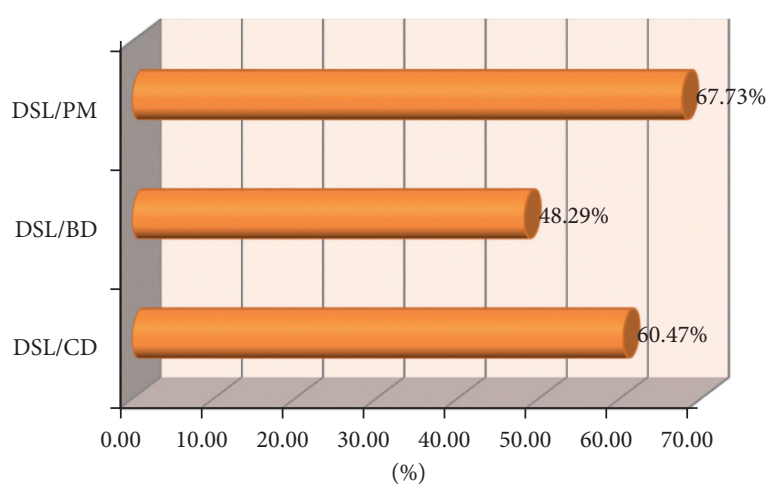

FIgURE 11: Volatile matter content of the briquettes with different binders.

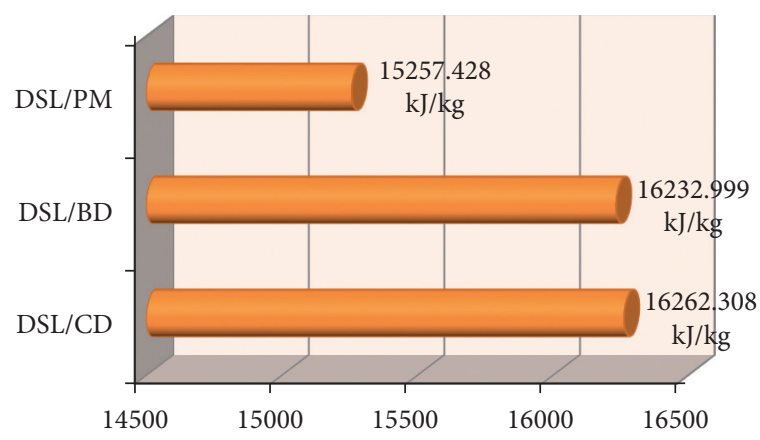

Figure 12: GCV of the briquettes with different binders.

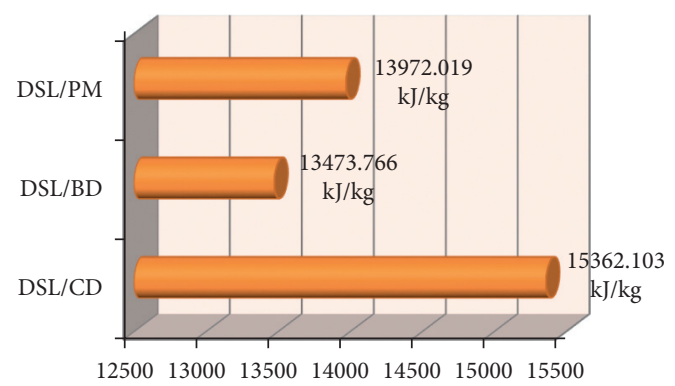

Figure 13: NCV of the briquettes with different binders.

The GCV and NCV are the main properties of briquettes. The higher the values of the GCV and NCV are, the higher the quality of the briquettes is. The GCV and NCV of DSL/CD were found to be $16262.31 \mathrm{~kJ} / \mathrm{kg}$ and $15362.1 \mathrm{~kJ} / \mathrm{kg}$, respectively, higher than those of DSL/BD and DSL/PM. The STS, TR, SR, and EDR of DSL/CD were found to be $7.164 \mathrm{kN} / \mathrm{m}^{2}, 87.84 \%, 12.75 \%$, and 0.9296 , respectively, higher than those of DSL/BD and DSL/PM. Therefore, it can be suggested that cow dung was the better binder for making high-quality dry sugarcane leaf briquettes compared with the buffalo dung and press mud binders. 


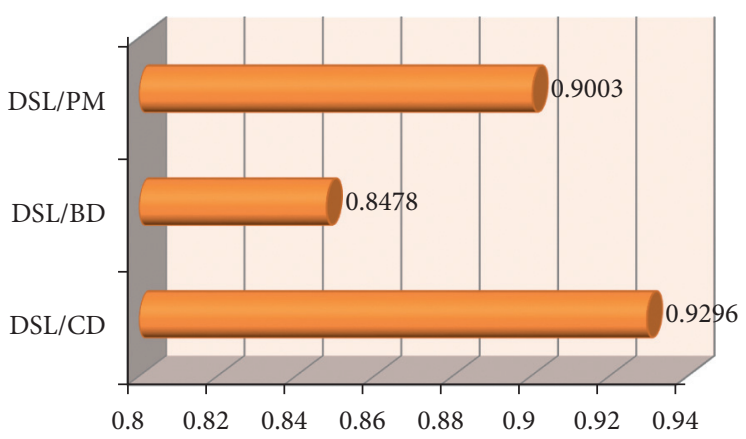

FIGURE 14: EDR of the briquettes with different binders.

TABLE 5: Comparison of the briquettes with different binders.

\begin{tabular}{lccc}
\hline & DSL/CD & DSL/BD & DSL/PM \\
\hline Physical properties & & & 191.9 \\
BD $\left(\mathrm{kg} / \mathrm{m}^{3}\right)$ & 198.1 & 216.8 & 171.31 \\
RD $\left(\mathrm{kg} / \mathrm{m}^{3}\right)$ & 169.47 & 174.95 & 1.923 \\
BD when using the water displacement method $\left(\mathrm{kg} / \mathrm{m}^{3}\right)$ & 3.28 & 3.46 & 0.001565 \\
DD & 0.033 & 0.1315 & 1.0015 \\
CR & 1.033 & 1.131 & 6.98 \\
STS $\left(\mathrm{kN} / \mathrm{m}^{2}\right)$ & 7.164 & 5.59 & 86.66 \\
TR $(\%)$ & 87.84 & 84.13 & Disintegrated after six drops \\
SR $(\%)$ & 12.75 & Disintegrated after seven drops & \\
Proximate analysis & & & 6.52 \\
Moisture $(\%)$ & 25.61 & 33.89 & 18.88 \\
Ash $(\%)$ & 10.99 & 9.86 & 6.87 \\
Fixed carbon content $(\%)$ & 2.93 & 7.96 & 67.73 \\
Volatile matter $(\%)$ & 60.47 & 48.29 & 15257.428 \\
GCV $(\mathrm{kJ} /$ Kg) & 16262.308 & 16232.999 & 13972.019 \\
NCV $(\mathrm{kJ} / \mathrm{Kg})$ & 15362.103 & 13473.766 & 0.90034 \\
EDR & 0.9296 & 0.8478 & \\
\hline
\end{tabular}

\section{Conclusions}

Dry sugarcane leaves are produced in huge quantities and usually burnt directly in an open atmosphere, creating environmental pollution. Dry sugarcane leaves have a GCV of $16919.667 \mathrm{~kJ} / \mathrm{kg}$, which can be converted into briquettes or otherwise be wasted. These briquettes are a good choice for generating energy for households and industrial applications. From the above results, the following conclusions can be drawn:

(1) The proximate analysis and physical properties of the briquettes estimated in this study show that cow dung is a better binder for making high-quality dry sugarcane leaf briquettes compared with the buffalo dung and press mud binders. The dry sugarcane leaf briquettes with the cow dung binder satisfy the main parameters required for high-quality briquettes. The highest values of the GCV, NCV, STS, TR, SR, and EDR were found to be $16262.31 \mathrm{~kJ} / \mathrm{kg}, 15362.1 \mathrm{~kJ} / \mathrm{kg}$, $7.164 \mathrm{kN} / \mathrm{m}^{2}, 87.84 \%, 12.75 \%$, and 0.9296 , respectively.

(2) We provided evidence that there is no need to add water during briquette making. Briquettes can be made using the moisture naturally present in dry sugarcane leaves and binders.

(3) A dry sugarcane leaf briquette has great potential to fulfil demand for energy.

(4) Dry sugarcane leaf briquettes can be short-term quick-fix solution for the energy problems faced by India.

\section{Data Availability}

The data used to support the findings of this study are included within the article. 


\section{Conflicts of Interest}

The authors declare that they have no conflicts of interest.

\section{References}

[1] L. Dai, N. Zhou, H. Li et al., "Recent advances in improving lignocellulosic biomass-based bio-oil production," Journal of Analytical and Applied Pyrolysis, vol. 149, pp. 1-49, 2020.

[2] M. Goyal and R. Jha, "Introduction of renewable energy certificate in the Indian scenario," Renewable and Sustainable Energy Reviews, vol. 13, no. 6-7, pp. 1395-1405, 2009.

[3] M. Guo, W. Song, and J. Buhain, "Bioenergy and biofuels: history, status, and perspective," Renewable and Sustainable Energy Reviews, vol. 42, pp. 712-725, 2015.

[4] A. J. Ragauskas, C. K. Williams, B. H. Davison et al., "The path forward for biofuels and biomaterials," Science, vol. 311, no. 5760, pp. 484-489, 2006.

[5] K. G. Nodooshan, R. J. Moraga, S.-J. G. Chen, C. Nguyen, Z. Wang, and S. Mohseni, "Environmental and economic optimization of algal biofuel supply chain with multiple technological pathways," Industrial \& Engineering Chemistry Research, vol. 57, no. 20, pp. 6910-6925, 2018.

[6] M. Kashanian, M. S. Pishvaee, and H. Sahebi, "Sustainable biomass portfolio sourcing plan using multi-stage stochastic programming," Energy, vol. 204, pp. 1-38, 2020.

[7] L. J. R. Nunes, T. P. Causer, and D. Ciolkosz, "Biomass for energy: a review on supply chain management models," Renewable and Sustainable Energy Reviews, vol. 120, pp. 1-8, 2020.

[8] G. Fisher and L. Schrattenholzer, "Global bioenergy potentials through 2050," Biomass and Bioenergy, vol. 20, no. 3, pp. 151-159, 2001.

[9] C. Karunanithy, Y. Wang, K. Muthukumarappan, and S. Pugalendhi, "Physiochemical characterization of briquettes made from different feedstocks," Biotechnology Research International, vol. 2012, Article ID 165202, 12 pages, 2012.

[10] R. M. Jorapur, A. K. Rajvanshi, P. J. Paul, and H. S. Mukunda, "Operating experience and economics of a $15 \mathrm{kVA}$ Genset gasifier system running on chopped sugarcane leaves," Recent Advances in Biomass Gasification and Combustion, pp. 257273, Interline Publishing, Bangalore, India, 1993.

[11] S. P. Rajput, S. V. Jadhav, and B. N. Thorat, "Methods to improve properties of fuel pellets obtained from different biomass sources: effect of biomass blends and binders," Fuel Processing Technology, vol. 199, pp. 1-12, 2020.

[12] H. Jain, Y. Vijayalakshmi, and T. Neeraja, "Preparation of briquettes using biomass combinations and estimation of its calorific value," International Journal of Science and Research, vol. 4, no. 3, pp. 322-324, 2015.

[13] M. Iftikhar, A. Asghar, N. Ramzan, B. Sajjadi, and W.-y. Chen, "Biomass densification: effect of cow dung on the physicochemical properties of wheat straw and rice husk based biomass pellets," Biomass and Bioenergy, vol. 122, pp. 1-16, 2019.

[14] C. Tiwari, "Producing fuel briquettes from sugarcane waste," in Proceedings of the 2011 National Research \& Education Conference Our Global Future EWB UK, Sheffield, UK, March 2011.

[15] A. K. Chandel, S. S. da Silva, W. Carvalho, and O. V. Singh, "Sugarcane bagasse and leaves: foreseeable biomass of biofuel and bio-products," Journal of Chemical Technology \& Biotechnology, vol. 87, no. 1, pp. 11-20, 2012.
[16] Food and Agricultural Organization of the United Nations, "Economic and social department, the statistical division," 2018, https://en.wikipedia.org/wiki/sugarcane.

[17] Department of Agriculture and Cooperation, "Horticulture division (2016) 128-185," 2018, http://eands.dacnet.nic.in/.

[18] R. H. Kaul, T. U. Ornvall, L. Gustafsson, and B. P. Orjesson, "Industrial biotechnology for the production of bio-based chemicals a cradle cradleto-grave perspective," Trends in Biotechnology, vol. 25, pp. 119-124, 2007.

[19] C. Somerville, H. Youngs, C. Taylor, S. C. Davis, and S. P. Long, "Feedstocks for lignocellulosic biofuels," Science, vol. 329, no. 5993, pp. 790-792, 2010.

[20] A. K. Chandel and O. V. Singh, "Weedy lignocellulosic feedstock and microbial metabolic engineering: advancing the generation of "biofuel," Applied Microbiology and Biotechnology, vol. 89, no. 5, pp. 1289-1303, 2011.

[21] A. Pandey, C. R. Soccol, P. Nigam, and V. T. Soccol, "Biotechnological potential of agro-industrial residues. I: sugarcane bagasse," Bioresource Technology, vol. 74, no. 1, pp. 69-80, 2000.

[22] P. R. Bonelli, E. L. Buonomo, and A. L. Cukierman, "Pyrolysis of sugarcane bagasse and co-pyrolysis with an argentinean subbituminous coal," Energy Sources, Part A: Recovery, Utilization, and Environmental Effects, vol. 29, no. 8, pp. 731-740, 2007.

[23] Y. Shinogi and Y. Kanri, "Pyrolysis of plant, animal and human waste: physical and chemical characterization of the pyrolytic products," Bioresource Technology, vol. 90, no. 3, pp. 241-247, 2003.

[24] B. V. Shinde and M. Singaravelu, "Bulk density of biomass and particle density of their briquettes," International Journal of Agricultural Engineering, vol. 7, no. 10, pp. 221-224, 2014.

[25] U. B. Deshannavar, P. G. Hegde, Z. Dhalayat, V. Patil, and S. Gavas, "Production and characterization of agro-based briquettes and estimation of calorific value by regression analysis: an energy application," Materials Science for Energy Technologies, vol. 1, no. 2, pp. 175-181, 2018.

[26] B. D. Kanawade, V. P. Kulkarni, S. B. Kandekar, and A. J. Mehetre, "Compression and split tensile strength of concrete containing different aggregates," International Journal of Engineering Research \& Technology, vol. 3, no. 3, pp. 469-473, 2014.

[27] A. Olorunnisola, "Production of fuel briquettes from waste paper and coconut husk admixtures, international commission of agricultural engineering (CIGR, Commission Internationale du Genie Rural)," E-Journal, vol. 9, 2007.

[28] N. Kaliyan and R. Vance Morey, "Factors affecting strength and durability of densified biomass products," Biomass and Bioenergy, vol. 33, no. 3, pp. 337-359, 2009.

[29] A. Demirbas, "Physical properties of briquettes from waste paper and wheat straw mixtures," Energy Conversion \& Management, vol. 40, pp. 437-445, 1999.

[30] R. F. Temmermana, M. T. Bohmb, H. H. Peter, J. Rathbauerd, J. Carrascoe, and M. Fernandeze, "Particle density determination of pellets and briquettes," Biomass and Bioenergy, vol. 30, no. 11, pp. 954-963, 2006.

[31] W. L. McCabe, J. C. Smith, and P. Harriott, Unit Operations of Chemical Engineering, McGraw Hill Book Co., Singapore, 5th edition, 1993.

[32] U. L. Steeter, Fluid Mechanics, McGraw Hill Book Co., New York, NY, USA, 5th edition, 1971.

[33] S. H. Sengar, A. G. Mohod, Y. P. Khandetod, S. S. Patil, and A. D. Chendake, "Performance of briquetting machine for 
briquette fuel," International Journal of Energy Engineering, vol. 2, no. 1, pp. 28-34, 2012.

[34] F. Karaosmanoglu, E. Tetik, B. Gurboy, and I. Sanli, "Characterization of the straw stalk of the rapeseed plant as a biomass energy source," Energy Sources, vol. 21, pp. 801-810, 1999.

[35] G. C. Wakchaure and I. Mani, "Effect of binders and pressures on physical quality of some biomass briquettes," Journal of Agricultural Engineering, vol. 46, no. 4, pp. 24-30, 2009.

[36] J. T. Oladeji, "Fuel characterization of briquettes produced from corncob and rice husk residues," Pacific Journal of Science and Technology, vol. 11, no. 1, pp. 101-106, 2010.

[37] A. Demirbas and A. Sahin, "Evaluation of biomass residue 1. Briquetting waste paper and wheat straw mixtures," Fuel Processing Technology, vol. 55, pp. 175-183, 1998.

[38] H. Qiang, S. Jingai, Y. Haiping, Y. Dingding, W. Xianhua, and C. Hanping, "Effects of binders on the properties of bio-char pellets," Applied Energy, vol. 157, pp. 508-516, 2015.

[39] N. Kaliyan and R. V. Morey, "Densification characteristics of corn cobs," Fuel Processing Technology, vol. 91, no. 5, pp. 559-565, 2010.

[40] M. Matus, P. Krizan, L. Soos, and J. Beniak, "The effect of papermaking sludge as an additive to biomass pellets on the final quality of the fuel," Fuel, vol. 219, pp. 196-204, 2018.

[41] S. Yaman, M. Şahan, H. Haykiri-açma, K. Şeşen, and S. Küçükbayrak, "Production of fuel briquettes from olive refuse and paper mill waste," Fuel Processing Technology, vol. 68 , no. 1 , pp. 23-31, 2000.

[42] A. Demirbas and A. S. Demirbas, "Briquetting properties of biomass waste materials," Energy Sources, vol. 26, no. 1, pp. 83-91, 2014.

[43] P. Jittabut, "Physical and thermal properties of briquette fuels from rice straw and sugarcane leaves by mixing molasses," Energy Procedia, vol. 79, pp. 2-9, 2015.

[44] R. Shuma and D. M. Madyira, "Production of loose biomass briquette from agricultural and forestry residues," Procedia Manufacturing, vol. 7, pp. 98-105, 2016.

[45] S. Mani, L. G. Tabil, and S. Sokhansanj, "Effects of compressive force, particle size and moisture content on mechanical properties of biomass pellets from grasses," Biomass and Bioenergy, vol. 30, no. 7, pp. 648-654, 2006.

[46] Ü. G. Beker, "Briquetting of Afşin-Elbistan lignite of Turkey using different waste materials," Fuel Processing Technology, vol. 51, no. 1-2, pp. 137-144, 1997.

[47] S. V. Vassilev, C. G. Vassileva, and V. S. Vassilev, "Advantages and disadvantages of composition and properties of biomass in comparison with coal: an overview," Fuel, vol. 158, pp. 330-350, 2015.

[48] J. O. Akowuah, F. Kemausur, and S. J. Mitchual, "Physicochemical characteristics and market potential of sawdust charcoal briquette," International Journal of Energy and Environmental Engineering, vol. 3, no. 20, pp. 1-11, 2012.

[49] S. V. Vassilev, D. Baxter, L. K. Andersen, C. G. Vassileva, and T. J. Morgan, "An overview of the organic and inorganic phase composition of biomass," Fuel, vol. 94, pp. 1-33, 2012.

[50] J. O. Chaney, Combustion characteristics of biomass briquettes, Ph.D. thesis, University of Nottingham, Nottingham, UK, 2010.

[51] S. V. Loo and J. Koppejan, The Handbook of Biomass Combustion and Co-Firing, Earthscan, London, UK, 1st edition, 2008.

[52] F. d. S. Costa and D. Sandberg, "Mathematical model of a smoldering log," Combustion and Flame, vol. 139, pp. 227238,2004 .
[53] I. Obernberger and G. Thek, The Pellet Handbook: The Production and Thermal Utilization of Biomass Pellets, Earthscan, London, UK, 1st edition, 2010.

[54] A. N. Efomah and A. Gbabo, "The physical, proximate and ultimate analysis of rice husk briquettes produced from a vibratory block mould briquetting machine," IJISET, vol. 2, no. 5, pp. 814-822, 2015.

[55] C. C. Enweremadu, J. O. Ojediran, J. T. Oladeji, and I. O. Afolabi, "Evaluation of energy potential of husks from soybeans and cowpea," Science Focus, vol. 8, pp. 18-23, 2004.

[56] S. A. Channiwala and P. P. Parikh, "A unified correlation for estimating HHV of solid, liquid and gaseous fuels," Fuel, vol. 81, no. 8, pp. 1051-1063, 2002. 